\title{
A DUPLA FACE DO PRINCÍPIO DA SOLIDADARIEDADE NA PERSPECTIVA FILOSÓFICA: RELATIVISTA E UNIVERSALISTA
}

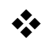 \\ Alexandre Brandão Rodrigues \\ Universidade de Santa Cruz do Sul - UNISC - Brasil
}

\section{Resumo}

O presente artigo trata do princípio da solidariedade na sua perspectiva filosófica e axiológica como dever moral da Humanidade. Identifica as origens do princípio da solidariedade na Filosofia Clássica: a sua face relativista, no relativismo cultural, bandeira do pós-modernismo, e na democracia deliberativa de Jürgen Habermas; e a sua face universalista, que tem como base a filosofia de Immanuel Kant e de Hans Jonas. Conclui-se que tanto o caráter relativista quanto o universalista compõem o conceito do princípio da solidariedade e não podem estar dissociados. É necessário que o Homem se atenha a sua responsabilidade como ser consciente e possuidor do poder da técnica, o que gera o dever moral e jurídico da solidariedade com o seu semelhante (presente e futuro), bem como com a Natureza.

Palavras chave: Princípio da Solidariedade. Relativismo Cultural. Universalismo.

\section{Introdução}

O princípio da solidariedade atua não propriamente como um direito fundamental, pois, como ensina Alexy (1999, p. 61), sua fundamentalidade é definida pelo papel decisivo (prioritário) que esse direito tem. Muitos homens têm carência fundamental ao amor, mas não existe um direito fundamental ao amor, porque ele não se dobra ao direito. Isso serve também para a solidariedade: ela não é um direito fundamental, não existe um direito fundamental à solidariedade, mas sim é um metaprincípio que orienta o trabalho hermenêutico filosófico da jurisdição e dos juristas em geral. Assim, o princípio da solidariedade serve como função otimizadora dos direitos fundamentais, principalmente dos direitos sociais e difusos.

Juntamente com o também metaprincípio da dignidade da pessoa humana, a solidariedade tem como fim potencializar e concretizar os valores fundamentais no Estado Democrático de Direito. Nesse sentido, Fontana e Reis (2011, p. 135) afirmam:

A solidariedade traz a socialização do direito, ou melhor, a atuação solidária, de maneira geral, realiza funções sociais que costumam constar em políticas públicas. Assim, o excesso de individualismo, que transformou o homem contemporâneo, é fruto de uma não recepção de condutas solidárias - expressadas desde o final do século XIX - ao longo dos tempos, provocando uma padronização nas ações dos 
indivíduos e uma ausência de trejeitos para a necessidade de visualizar a coletividade.

O princípio da solidariedade pode (e deve) ser visto sob dois pontos de vista: o externo (ético-político) e o interno (propriamente jurídico) do ordenamento jurídico. O ponto de vista externo é o caráter ético-político, axiológico, sociológico, referente a finalidades, valores e interesses (FERRAJOLI, 2006, p. 833) que penetram no ordenamento jurídico ${ }^{1}$. E é sob este aspecto - o ponto de vista externo do princípio da solidariedade -, mais propriamente filosófico (axiológico), que se dará a reflexão desse trabalho.

Pretende-se, pois, através de uma abordagem que vai desde a antiguidade até a pósmodernidade, descortinar os fundamentos axiológicos do princípio da solidariedade.

\section{Sócrates e os sofistas - início da controvérsia entre relativismo e universalismo. Filosofia clássica como germe do princípio da solidariedade}

Protágoras ${ }^{2}$, com a sua célebre frase: "O homem é a medida de todas as coisas" foi o precursor do relativismo. Entendia o célebre sofista que todo o argumento tem dois lados e que ambos podem ser considerados válidos, dependendo dos valores, da crença e da cultura de determinado homem ou de determinada sociedade (OSBORNE, 2011). A esta concepção relativista do mundo, mas principalmente dos valores, se opôs Sócrates ${ }^{3}$. Entendia o célebre filósofo que a virtude (aretê) era um valor universal, que a sua definição não poderia ficar a critério de determinado homem ou sociedade. E a forma de se alcançar a virtude é por meio do conhecimento (RUSSEL, 2013).

Segundo Sócrates, as virtudes são a justiça, a coragem, a temperança e a sabedoria, que formam uma unidade de sentido. Essa unidade das virtudes não significava propriamente

\footnotetext{
${ }^{1}$ Nesse ponto, há uma divergência entre duas perspectivas teóricas: o Constitucionalismo Garantista de Luigi Ferrajoli e o Neoconstitucionalismo, que tem como principais expoentes Robert Alexy e Ronald Dworkin. Ambas concordam com a necessidade de certos valores éticos-políticos penetrarem no sistema jurídico, mas divergem sobre o modo que deve se dar essa penetração. O Neoconstitucionalismo tem uma concepção comunitária, impregnada de aspectos valorativos e éticos, destacando uma visão humanística, na qual os direitos fundamentais não constituem uma ordem neutra, mas fornecem princípios objetivos para pautar a vida em comum. Já o Constitucionalismo Garantista tem uma perspectiva teórica ligada à filosofia analítica que Ferrajoli denomina de "positivismo crítico", não puramente positivista (ou positivista dogmático), pois inova no sentido de reintroduzir os valores para dentro do sistema jurídico. Segundo ele, "em cada caso, os valores não são exorcizáveis: expulsos pela porta, entram novamente pela janela. E, no fundo, é bom que assim seja". (FERRAJOLI, 2006, p. 806)

${ }^{2}$ Filósofo grego que viveu entre 490 a 420 a. C., foi um dos principais expoentes da Escola Sofista, que tinha como principal característica o uso da retórica para defesa de qualquer ideia ou pessoa. (BUCKINGHAM, 2011).

${ }^{3}$ Filósofo grego que viveu entre 469 a 399 a. C., é considerado um dos fundadores da filosofia ocidental. Foi precursor das escolas filosófica estoica e cínica e teve como principal discípulo Platão, que registrou as suas ideias. (BUCKINGHAM, 2011).
}

Barbarói, Santa Cruz do Sul, Edição Especial n.47, p.<209-222>, jan./jun. 2016 
que elas sejam idênticas umas das outras, mas que têm unidade como identidade, no sentido que

Segundo a Tese da Identidade, Sócrates sustenta que há uma única forma de conhecimento (o "conhecimento do bem e do mal") que é a chave para a ação justa, corajosa e virtuosa em geral. Esse conhecimento garante que o juízo de alguém sobre como agir será correto, bem como se agirá de forma correspondente, visto que o desejo do agente estará propriamente dirigido ao bem. (DEVEREUX, 2011, p. 305)

A tese da identidade (também da inseparabilidade) das virtudes causou controvérsia, inclusive com o principal discípulo de Sócrates, Platão, que via certa contradição na tese, pois, por exemplo, em certas ocasiões ser sábio é o contrário de ser corajoso. Mas, o último componente do trio de ouro da filosofia da Antiguidade, Aristóteles, discípulo de Platão, lançou mais luzes para a solução da controvérsia.

Aristóteles entendia que o segredo da vida boa é a busca da eudaimonia, que significa "prosperidade", "felicidade". Essa busca se dá em sociedade, cultivando-se bons padrões de comportamentos (virtudes) e evitando-se os maus (vícios). Mas, para Aristóteles, a virtude está no meio entre dois extremos. Assim, para se utilizar o exemplo dado quanto à coragem, esta virtude para Aristóteles está entre a covardia e a temeridade.

No pensamento destes filósofos clássicos - Sócrates, Platão e Aristóteles - está o germe filosófico do princípio da solidariedade, visto na sua perspectiva universalista, do cultivo às virtudes para se bem viver em sociedade, pois, para o Ser Humano não há forma possível de vida fora da sociedade. Somente de forma solidária é possível ter uma vida virtuosa, boa, eudêmica.

Certo que o relativismo sofista foi visto de maneira pejorativa ao longo da história, isso devido ao seu apelo egoístico, visando lucro, não tendo apreço com a verdade ao defender qualquer ideia, desde que fosse pago para isso. Por essa razão, a filosofia de Sócrates, Platão e Aristóteles, por milênios, foi dominante no pensamento ocidental. Isso só começou a mudar no final do século XIX e início do século XX, com a filosofia de Nietzsche $^{4}$, Heidegger ${ }^{5}$ e Kierkegaard ${ }^{6}$ que influenciaram fortemente o Estruturalismo. Este

\footnotetext{
${ }^{4}$ Friedrich Nietzsche (1844-1900) - ao "filosofar com o martelo" atacou a filosofia ocidental até então vigente, principalmente os conceitos de: homem, Deus e moralidade. Suas principais obras são: O nascimento da tragédia (1872); Assim falou Zaratustra (1883); Para além do bem e do mal (1886); Crepúsculo dos ídolos (1888). (BUCKINGHAM, 2011)

${ }^{5}$ Martin Heidegger (1889-1976) - filósofo alemão muito controvertido pelas suas ligações com o Partido Nazista na Alemanha. Propôs a análise mais concreta e menos abstrata do ser, ou seja, fenomenológica, investigando os fenômenos de acordo com a experiência que se tem em relação a eles. Suas principais obras são: Ser e tempo
} 
movimento filosófico rejeita todo tipo de unidade e objetividade, e propõe uma desconstrução e crítica de toda a "verdade". O Estruturalismo ficou mais conhecido como "PósModernismo".

\section{$O$ relativismo cultural e a democracia deliberativa no respeito à diversidade e às minorias: a outra face da solidariedade}

Segundo Carlos Alberto Elbert (2012), a Pós-Modernidade surgiu no campo das ciências no início do século XX, como crítica à Modernidade, pois entendia que esta era uma utopia que já acabou e que os seus projetos tiveram fim. Fato este que os pós-modernistas sequer se preocupam em comprovar, visto que não admitem um conceito homogêneo de nada, o que não permite a classificação. Pretendem superar a Modernidade, mas, ocorre que esta refutação definitiva e completa da Modernidade ainda não foi alcançada. Até porque, no mundo atual, os valores fundamentais da Modernidade continuam funcionando, como por exemplo, a permanência das instituições republicanas, as hierarquias acadêmicas, entre outros.

Os principais referenciais teóricos do movimento pós-modernista foram os franceses Jacques Derrida ${ }^{7}$ e Michel Foucault ${ }^{8}$, mas também se pode citar expoentes como Louis Althusser, Ferdinand de Saussure, Jean-Fançois Lyotard, Paul Feyerabend, Jacques Lacan entre muitos outros nomes. A Pós-Modernidade busca o conhecimento pela crítica da racionalidade e pelo desprezo de toda ideia logocentrista, que é difundida "em distintas disciplinas, desencadeando escândalo, confusão, intensos debates e também uma forte repercussão”. (ELBERT, 2012, p. 47) A ideia central do movimento é a desconstrução, não só da linguagem, mas de toda a forma de poder, em especial o saber, por isso desqualificam

(1927); A superação da metafísica (1936-53); A essência do fundamento (1955); Identidade e diferença (195557). (BUCKINGHAM, 2011)

${ }^{6}$ Seren Kierkegaard (1813-1855) - filósofo dinamarquês que se caracterizou por se contrapor a filosofia idealista alemã, principalmente por refutar a ideia de Hegel de sistema completo. É considerado como pai do existencialismo. Suas principais obras são: Temor e tremor (1843); Ou isso ou aquilo (1843); O conceito da angústia (1844); As obras do amor (1847). (BUCKINGHAM, 2011)

${ }^{7}$ Jacques Derrida (1930-2004): tem o seu nome associado à ideia de desconstrução. Endente que todos são mediadores, tradutores de um texto, mesmo os mais diretos, visto que estão crivados de "aporias" (contradições). E, ao explorar as aporias, encontram-se coisas diferentes. É um modo de ler os textos para descortinar os seus paradoxos e contradições. Tem como principais obras: Gramatologia (1967); A escritura e a diferença (1967); A voz e o fenômeno (1967); Políticas da amizade (1994). (BUCKINGHAM, 2011)

${ }^{8}$ Michel Foucault (1926-1984): entendia, basicamente, que o que o homem pensa é formado por um conjunto de regras inconscientes, fixadas por condições históricas (senso comum). Tais regras mudam constantemente, ao longo do tempo e, também, os nossos discursos. Por isso, a nossas ideias atuais não podem ser aplicadas a outro ponto qualquer da história da humanidade. A ideia de ser humano como fundamental e imutável é errônea, a ideia de "homem" é uma invenção recente que iniciou no século XIX e que pode, inclusive, estar perto do seu fim. Tem como principais obras: História da loucura (1961); O nascimento da clínica (1963); A palavras e as coisas: uma arqueologia das ciências humanas (1966); Vigiar e punir (1975). (BUCKINGHAM, 2011) 
todo relato metódico e linear, que consideram como forma de dominação pelo discurso, a ponto de excluir a todos que não se enquadram na proposta epistemológica oficial. (ELBERT, 2012)

A proposta pós-modernista de forma alguma pretende substituir a Modernidade, mas sim “desmistificá-la, desqualificá-la como relato histórico, desconstruindo as suas bases de sustentação" (ELBERT, 2012, p. 49) e assim, possibilitar uma maior liberdade de pensamento, sem as amarras lógicas da Modernidade. É possível fazer a "transvaloração dos valores" "9 sem abrir mão de nossa cultura, sem despojar-nos de nossa história. É possível também fazer a crítica ao endeusamento da razão, denunciar as manobras espúrias dos poderosos, refutar o pensamento e a cultura etnocêntrica sem, contudo, prescindir dos valores universais que nos foram legados pela cultura da Modernidade.

O Pós-Modernismo foi acusado de ser um movimento de intelectuais da elite que propõe a desconstrução dos valores culturais ora dominantes, por meio de uma análise crítica de esquerda, sem, contudo, o devido apelo popular. Suas bases teóricas foram consideradas por demais abstratas e, por vezes, inacessíveis e desconectadas com o mundo. Nesse sentido:

\begin{abstract}
A adoção do ideal pós-moderno requer, de nós, o ceticismo sobre tudo o que pensemos e tudo o que aconteça, ordenando a experiência em uma indefinição que não pode conduzir senão ao niilismo, à impotência ante aos acontecimentos ou à redução dos esforços humanos à insignificância. Tais renúncias implicam, neste momento da história, um sacrifício enorme, que também poderia ser interpretado como um exercício de poder; a compulsão ao niilismo, pelo caminho da desconstrução de toda a lógica. (ELBERT, 2012, p. 50)
\end{abstract}

Mas a pós-modernidade, diferente dos sofistas que viam no relativismo somente uma forma de auferir lucros, faz uma crítica à opressão dos valores dominantes e do poder absoluto e desmedido, o que gera a necessidade de se reconhecer e respeitar o diferente. $\mathrm{O}$ relativismo cultural critica de forma intransigente (e justa) o etnocentrismo cultural, exige o respeito ao pluralismo cultural. Nesse ponto, entende que uma determinada cultura somente pode ser analisada (e criticada) no seu próprio contexto cultural. Eis a grande contribuição do

\footnotetext{
${ }^{9}$ Nas palavras de Nietzsche: "Em suma, desde que para mim se abriu essa perspectiva, tive razões para olhar em torno, em busca de camaradas doutos, ousados e trabalhadores (ainda hoje olho). O objetivo é percorrer a imensa, longínqua e recôndita região da moral — da moral que realmente houve, que realmente se viveu — com novas perguntas, com novos olhos: isto não significa praticamente descobrir essa região?... Se para isso pensei no mencionado dr. Rée, entre outros, isto ocorreu por não duvidar que a natureza mesma das suas questões o levaria a métodos mais corretos para alcançar as respostas. Teria me enganado nisso? Meu desejo, em todo o caso, era dar a um olhar tão agudo e imparcial uma direção melhor, a direção da efetiva história da moral, prevenindo-o a tempo contra essas hipóteses inglesas que se perdem no azul. Pois é óbvio que uma outra cor deve ser mais importante para um genealogista da moral: o cinza, isto é, a coisa documentada, o efetivamente constatável, o realmente havido, numa palavra, a longa, quase indecifrável escrita hieroglífica do passado moral humano!.” (NIETZSCHE, 1995, pp. 12 e 13)
} 
Movimento Pós-Moderno que, junto com a crítica à Modernidade e a exigência da desconstrução dos valores essenciais ao poder e ao saber, exigiram o respeito e consideração com o diferente. Portanto, o relativismo cultural que compõe o movimento exige que seja respeitada e considerada a pessoa (o grupo, a sociedade) por ser (e querer ser) diferente.

Nessa perspectiva inclusiva, abre-se caminho, na sociologia, para democracia deliberativa de Jurgen Habermas ${ }^{10}$. Entende esse filósofo que os sujeitos devem se reconhecer como livres e iguais e assim interagir em um processo comunicativo sem garantia de sucesso. Estabelece-se, desse modo, um acordo racional motivado no advento de um conflito. Esse objetivo é alcançado quando os participantes distanciam-se das próprias posições e se propõe a construir um consenso (princípio da universalização) por meio da apresentação de discursos razoáveis (princípio do discurso). Esse consenso é formado em dois polos distintos: nos espaços oficiais (sistema político-institucional) e nos espaços informais (sociedade lato sensu).

A democracia só é legitimada com a institucionalização jurídica dos procedimentos de legiferação (espaço institucional), convergindo com a construção de uma opinião informal no espaço público. Essa construção da opinião informal surge de forma espontânea, desorganizada, quase selvagem. Diferente da opinião institucional que está preocupada em estabelecer procedimentos para estruturar a formação da vontade popular com o fim de solucionar questões práticas. E é na relação desses dois extremos que devem ser tomadas as decisões dentro de uma sociedade: a esfera pública determinando os problemas que devem ser tratados pela esfera política. Partindo de um consenso comunicativo, a sociedade civil transmite ao poder público as questões trabalhadas na esfera pública para que possam ser articuladas e processadas na formação da verdade democrática.

E é nesse ponto, na inclusão do diferente, no respeito com a diversidade e de suas opiniões que se ressalta a outra face do princípio da solidariedade. Não há como se respeitar e considerar a pessoa por ser diferente sem se solidarizar por ela. Hoje, diante da globalização (um efeito da Pós-Modernidade) que tem o poder de unir as diferentes culturas, os diferentes credos, as diferentes etnias, o princípio da solidariedade não é só necessário, mas essencial para que se viva de forma harmônica.

\footnotetext{
10 Jürgen Habermas (1929 - ) - nasceu na Alemanha. Estudou com Horkheimer e Adorno, membros da Escola de Frankfurt. Foi professor de filosofia da Universalidade de Frankfurt até a sua aposentadoria em 1993. De acordo com Habermas, a sociedade necessita estabelecer uma critica constante de suas tradições por meio de um constante debate realizado na "esfera pública". (BUCKINGHAM, 2011)
} 
Porém, não é só na diferença que deve existir a solidariedade, trata-se de apenas um aspecto desse princípio. Não se pode admitir que por respeito à cultura de determinado povo se permita mutilações de mulheres, estupros e outras práticas que atentam contra os direitos humanos. O respeito e a consideração da diversidade é uma das faces da solidariedade que não está (e não pode estar) dissociada do seu aspecto universal, que representa o reconhecimento e o respeito de todos os Seres Humanos como iguais em dignidade. Nessa perspectiva universalista sobre a moral é imprescindível a análise do pensamento de Immanuael Kant ${ }^{11}$ e Hans Jonas ${ }^{12}$.

\section{$O$ imperativo categórico do respeito à dignidade humana (kant) e a ética da resposnsabilidade (hans jonas)}

A filosofia de Kant é por demais densa, pois ela estabelece, com o seu idealismo transcendental, uma ponte entre o empirismo e o racionalismo. No tocante à moralidade, Kant funda um sistema de imperativos categóricos, que são comandos "sem referência a nenhum outro propósito e sem depender de nenhum outro propósito". (SANDEL, 2011, pp. 151-152) Isso porque, para o filósofo, a atividade moral serve, exclusivamente, para o cumprimento de um dever (moral). Kant parte do pressuposto essencial que as pessoas são Seres Humanos e como tal são dotadas de dignidade. E é da capacidade do Ser Humano de fazer uso da razão que se desenvolve uma ética universalmente válida. Repele, portanto, toda e qualquer tentativa heterônoma

de fundamentar a ética a algo externo, em tradições, na vontade de Deus, em necessidades, são rejeitadas por Kant, rejeitando, assim, todas as pretensões de validade externas e de argumentando que toda autoridade tem de se justificar perante a razão. (NODARI, 2009, p. 159)

A moral para Kant é uma sucessão de imperativos categóricos (deveres absolutos) que representam uma ação válida por si mesma, sem nenhuma outra finalidade. Entendia que as regras de condutas são válidas para todos, por isso são imperativos. Esses imperativos podem

\footnotetext{
${ }^{11}$ Immanuel Kant (1724-1804): viveu e morreu na cidade de Konigsberg (Prússia), onde lecionou filosofia na universalidade local. Tornou-se um filósofo internacionalmente conhecido pela Teoria do Idealismo Transcendental, que faz uma ponte entre o Racionalismo e o Empirismo. Tem como principais obras: Crítica da razão pura (1781); Fundamentação da metafísica dos costumes (1785); e Crítica da razão prática (1788). (BUCKINGHAM, 2011)

${ }^{12}$ Hans Jonas (1903 - 1993) - Nascido em uma família judaica em Menchevgladback, Alemanha. Discípulo de Heidegger, que teve como mentor intelectual, acompanhando-o na transferência da Universalidade de Freiburg para a Universalidade de Marburg. Posteriormente, com o advento do nazismo, abandona a Alemanha. Na sua obra, busca uma nova base ética: "ética da responsabilidade". (JONAS, 2006)
} 
ser hipotéticos, quando uma ação é boa para outra coisa, mas não em si mesma; ou categóricos, "quando impõem à vontade uma acção. Não como meio para outra coisa, mas absoluta e incondicionalmente, como objecto necessário em si mesma”. (MORUJÃO, 1991, p. 129) Assim,

\begin{abstract}
enquanto os imperativos hipotéticos relacionam-se com a escolha dos meios de alcançar qualquer outra coisa que se quer como fim, eles não ordenam a ação de maneira absoluta, mas tão-somente como meio para outra finalidade, o categórico, por sua vez, não se baseia em qualquer outro interesse senão o interesse moral de agir à luz dos princípios da razão por dever de acordo com determinado comportamento racional.(NODARI, 2009, p. 159)
\end{abstract}

Diante dessa natureza absoluta e incondicional, advém a sua natureza geral e sua condição de ser obrigatória para todo o Ser Humano racional. Kant formula então a sua lei universal: "Age como se a máxima da tua acção se devesse tornar, pela tua vontade, em lei universal da natureza". (KANT, 2007, p. 59) De forma simplificada é a regra de ouro: "Não faça aos outros aquilo que você não gostaria que fizessem a ti”. Esse primeiro imperativo categórico trata-se de uma noção básica de civilidade que se traduz em uma lei universal.

O segundo imperativo categórico é o de agir de modo a tratar qualquer pessoa com respeito e dignidade, nunca a tratando como um meio para os fins que não são os seus:

\footnotetext{
O homem, e, duma maneira geral, todo o ser racional, existe como fim em si mesmo, não só como meio para o uso arbitrário desta ou daquela vontade. Pelo contrário, em todas as suas acções, tanto nas que se dirigem a ele mesmo como nas que se dirigem // a outros seres racionais, ele tem sempre de ser considerado simultaneamente como fim. (KANT, 2007, p. 68)
}

Ambos imperativos de Kant tem um cunho universal e devem ser observados para todas as pessoas, independente da cultura, da religião, da etnia, da opção sexual. E, com certeza, dão suporte moral a qualquer Estado civilizado, a qualquer Estado que seja Democrático de Direito.

Contudo, segundo Hans Jonas, tais imperativos categóricos não bastam para uma sociedade globalizada e tecnológica. A ética tradicional, fundada dentro dos limites do Ser Humano, exclui a Natureza como objeto da responsabilidade humana. Assim, propõe a substituição dos antigos imperativos éticos, em especial do imperativo kantiano: "Age como se a máxima da tua acção se devesse tornar, pela tua vontade, em lei universal da natureza"; por um novo imperativo de responsabilidade:

aja de modo a que os efeitos da tua ação sejam compatíveis com a permanência de uma autêntica vida humana sobre a Terra"; ou expresso negativamente: "aja de 
modo a que os efeitos da tua ação não sejam destrutivos para a possibilidade futura de uma tal vida". (JONAS, 2006, pp. 47-48)

Para Jonas (2006), o pressuposto da responsabilidade é a existência de homens conscientes. Ocorre que o imperativo tecnológico elimina a consciência e, consequentemente, a liberdade, em prol de uma espécie de determinismo. A hiperespecialidade da ciência mutila a noção de Ser Humano, visto que há uma ruptura entre reflexão ética e progresso científico que exige uma nova dimensão de responsabilidade: uma responsabilidade como um compromisso com o futuro, sobretudo, um compromisso com as futuras gerações. Trata-se de um imperativo que resguarda a existência dos indivíduos e da Natureza.

O poder que o Homem atingiu na era tecnológica é a fonte de sua responsabilidade, da sua responsabilidade com o outro Homem, com o Homem futuro e com a Natureza. Assim, o reducionismo antropocêntrico deve ser afastado e o Homem deve ter consciência que a sua grave responsabilidade que tem a mesma dimensão do seu poder:

\footnotetext{
O reducionismo antropocêntrico, que nos destaca e nos diferencia de toda a natureza restante, significa apenas reduzir e desumanizar o homem, pois atrofia a sua essência, na hipótese mais otimista da sua manutenção biológica, contradiz o seu objetivo expresso, a sua preservação sancionada pela dignidade do seu Ser. Em uma perspectiva verdadeiramente humana, a natureza conserva a sua dignidade, que se contrapõe ao arbítrio do nosso poder. Na medida em que ela nos gerou, devemos fidelidade à totalidade de sua criação. A fidelidade ao nosso Ser é apenas o ápice. Entendido corretamente, o ápice abrange o restante. (JONAS, 2006. p. 229)
}

Nessa perspectiva universal, o princípio da solidariedade está consubstanciado: no respeito que devemos ao outro, por ser detentor de dignidade como Ser Humano (primeiro e segundo imperativos kantianos); no respeito ao outro que virá a existir (as próximas gerações), devido à responsabilidade que temos pelo poder que advém de nossa técnica; e pelo respeito à Natureza, por ser fonte de tudo que existiu, do que existe e do que virá a existir.

\section{Conclusões}

Em sua obra pouco conhecida, "Teoria dos Sentimentos Morais", de 1759, Adam Smith, "o Pai da Economia", trata do egoísmo da sociedade e da necessidade de solidariedade (sympathy). Ressalta a necessidade de se opor ao egoísmo dominante e de se interessar pelas outras pessoas: 
Por mais egoísta que se suponha o homem, evidentemente há alguns princípios em sua natureza que o fazem interessar-se pela sorte dos outros, e considerar a felicidade deles necessária para si mesmo, embora nada extraia disso senão o prazer de assistir a ela. (SMITH, 2002, p. 5)

O filósofo escocês salienta que a harmonia da sociedade depende da solidariedade ou simpatia entre os sentimentos do ator e do espectador, o que garante um processo de regulação moral e a estabilidade do sistema social:

\begin{abstract}
Assim como a solidariedade (sympathy) destes os faz ver tal situação em certa medida com os olhos do sofredor, também sua solidariedade (sympathy) o faz considerá-la em certa medida com os olhos deles, especialmente quando em sua presença e agindo sob sua observação. E, como a paixão refletida que ele assim concebe é muito mais débil que a original, necessariamente reduz a violência do que sentia antes de estar em presença dos espectadores, antes de começar a lembrar de que maneira seriam afetados, e antes de considerar sua própria situação sob esta luz franca e imparcial. (SMITH, 2002, p. 23)
\end{abstract}

Certamente que a solidariedade a que se refere Adam Smith (2012) está muito mais para empatia que para solidariedade propriamente dita. De fato, da solidariedade pode surgir de um sentimento de empatia, de consideração, de afeto ou de amor com o outro, com o seu semelhante, mas, mesmo que tais sentimentos não brotem na alma do interlocutor, este não deixa de ter a obrigação de ser solidário. Isso porque a solidariedade é muito mais que um mero sentimento de compaixão, mas é um dever moral e jurídico.

Em busca das raízes morais (axiológicas) do princípio da solidariedade, não há como fugir do debate entre o universalismo e o relativismo, que sempre esteve presente na história da filosofia. O embrião da solidariedade encontra-se na filosofia clássica, a começar por Sócrates e a sua defesa dos valores universais contra a perspectiva relativista sofista, que não tinha compromisso com a verdade. E, depois, com Aristóteles, na busca da eudaimonia, que só se consegue no convívio em sociedade, cultivando virtudes e repelindo os vícios.

A filosofia clássica influenciou todo pensamento ocidental por milênios, o qual se revezava ora por Aristóteles, ora por Platão. A questão é que o universalismo, agora representado pela Modernidade, serviu para que se mantivesse o poder nas mãos de determinadas classes sociais, enquanto no campo do saber a epistemologia oficial, metódica e linear, afastava todo e qualquer conhecimento que não dominasse a sua técnica. Foi somente depois de Kierkegaard, Nietzsche, Heidegger e dos pensadores pós-modernistas como Derrida, Foucault, Althusser, Saussure, Feyerabend, entre outros, que o pensamento universalista perdeu espaço para o relativismo cultural, que valoriza e agrega os movimentos culturais da minoria, antes excluída. Surge assim, a outra face do princípio da solidariedade, ancorada no respeito e na consideração com o diferente. Nesse momento, ganha destaque o 
pensamento de Habermas voltado à democracia deliberativa, que tem como escopo agregar dentro do espaço público todas as minorias.

$\mathrm{O}$ respeito à cultura de uma determinada sociedade ou dos valores de determinados grupos não pode ser obstáculo para se questionar se essa cultura ou valores não ofendem outros valores que são universais, por exemplo, a dignidade da pessoa humana. Por isso, com base no respeito à diversidade cultural, não se pode permitir a mutilação generalizada do clitóris das meninas, o estupro coletivo, entre outras atrocidades. $\mathrm{O}$ respeito à diversidade cultural deve ser compatibilizado com o respeito a valores universais e, nesse ponto, temos em Kant e Hans Jonas os parâmetros necessários para aferir os valores universais.

Em Kant tem-se o primeiro e o segundo imperativos, ou seja, a condição de agir de tal modo que a ação se torne uma lei universal (regra de ouro) e o respeito intransigente à dignidade da pessoa humana. E em Hans Jonas há a expansão desses imperativos, estendendoos não só às pessoas existentes, mas também às futuras gerações e à Natureza como um todo. Isso devido ao grande poder que temos oriundo de nossa técnica, que gera a nossa responsabilidade com a humanidade presente, futura e com todo o ser vivente que habita o planeta (no caso, com a Natureza).

Segundo Boaventura, é necessário superar o debate sobre universalismo e relativismo, pois "trata-se de um debate intrinsecamente falso, cujos conceitos polares são igualmente prejudiciais para uma concepção emancipatória de direitos humanos ${ }^{13}$. Assim, no campo ético/moral o princípio da solidariedade tem dupla face: a primeira está no respeito e reconhecimento do ser humano por ser diferente, no direito à diversidade; e a segunda está no respeito e no reconhecimento do ser humano por ser igual, tanto em direitos, como em dignidade. E, também, a solidariedade diante da responsabilidade que o Homem deve ter por ser um ser consciente e por ter o poder do domínio da técnica, solidariedade com as futuras gerações de seres conscientes (humanos), bem como com os seres semiconscientes e inconscientes que habitam a Natureza.

Portanto, como se disse, a solidariedade não se trata de um mero sentimento, mas sim de um dever moral, ético ${ }^{14}$ com o semelhante e com a Natureza. Desse modo, a grave crise

\footnotetext{
${ }^{13}$ SOUSA SANTOS, Boaventura de Sousa. Por uma concepção multicultural de direitos humanos. In: SOUSA SANTOS, Boaventura de (org.). Reconectar para libertar. Os caminhos do cosmopolismo multicultural. Rio de Janeiro: Civilização Brasileira, 2003, p. 18.

${ }^{14}$ E também jurídico, tanto no Direito Interno, como no Direito internacional. No Direito Interno, mais propriamente, na Constituição da República, ela está no inciso I do artigo $3^{\circ}$ que dispõe que um dos objetivos da República é "construir uma sociedade livre, justa e solidária". No campo do Direito Internacional está no artigo $1^{\circ}$ da Declaração Universal dos Direitos do Homem da ONU, de 1948, que dispõe: "Todos os homens nascem livres e iguais em dignidade e direitos. São dotados de razão e consciência e devem agir em relação uns aos
} 
que passa a Europa por conta dos imigrantes das zonas de guerra do Oriente Médio se trata, antes de tudo, de uma crise moral. Primeiro porque demonstra que os governantes europeus e parte do povo não consegue viver com a diversidade. E, ainda, não é só neste aspecto da solidariedade que está sendo negligenciado, existe também a degradação da dignidade de homens, mulheres e crianças, muitos morrendo nas fronteiras da Europa enquanto os europeus estão preocupados com a sua economia. Não há dúvida que há uma grande crise ética de cunho solidário (tanto no seu caráter de respeito à diversidade, como na sua condição de respeito à dignidade humana) na Europa atualmente.

Além disso, o egocentrismo entorpece a consciência da Humanidade. Urge que a Humanidade desperte para uma consciência mais cosmocêntrica (ROHDEN, 2008) e para os valores e deveres oriundos da responsabilidade advinda do poder que o Homem detém neste planeta. Só assim, se poderá viver de maneira mais "livre, justa e solidária”.

\title{
THE DOUBLE FACE OF THE PRINCIPLE OF SOLIDARITY IN THE PHILOSOPHICAL PERSPECTIVE: RELATIVIST AND UNIVERSALIST
}

\begin{abstract}
This paper talks about the solidarity principle in its philosophic and axiological perspective as a Humanity moral duty. It identifies the origins of the solidarity principle in Classic Philosophy such as its relativist side, in cultural relativism, post-modernism flag and in Jürgen Habermas deliberative democracy; an also its universalist side that has as base the Immanuel Kant's and Hans Jonas' philosophies. It is clear that as the Relativist character as the Universalist compose the concept of the solidarity principle and cannot be dissociated. It is necessary that humankind lean on his responsibility as a conscious being and owner of the power of technique, which generates the moral and legal duty of solidarity toward his equals (present and future ones) as well as Nature.
\end{abstract}

Keywords: Solidarity principle. Cultural Relativism. Universalism.

\section{Referências}

ALEXY, Robert. Teoria dos direitos fundamentais. Tradução de Virgílio Afonso da Silva. 2. edição. São Paulo: Malheiros, 2008.

Os direitos fundamentais no Estado Constitucional democrático. In: Revista do Direito Administrativo, Rio de Janeiro, n. 217, jul./set.. 1999.

BARRETTO, Vicente de Paulo (Coord.). Dicionário de filosofia do direito. São Leopoldo: Editora Unisinos; Rio de Janeiro: Renovar, 2006.

outros com espírito de fraternidade". Mas, como se disse no início, a perspectiva jurídica é tema a ser abordado em outro artigo.

Barbarói, Santa Cruz do Sul, Edição Especial n.47, p.<209-222>, jan./jun. 2016 
BUCKINGHAM, Will et al. O Livro da Filosofia. Tradução Douglas Kim. São Paulo: Globo, 2011.

DEVEREUX, Daniel. A unidade das virtudes. In: BENSON, Hugh H.. Platão.Tradução: Marco Antônio de Ávila Zingano. Porto Alegre: Artmed, 2011.

DWORKIN, Ronald. O império do Direito. Tradução de Jefferson Ruiz Camargo. 2. edição. São Paulo: Martins Fontes, 2007.

ELBERT, Carlos Alberto. Criminologia, ciência e mudança social. Tradução de Carlos Pereira Thompson e Mariana Chies dos Santos; tradução e revisão de Ney Fayet Júnior. Porto Alegre: Núria Fabris Ed., 2012.

FERRAJOLI, Luigi. Direito e razão. Tradução de Ana Paula Zomer Sica, Fauzi Hassan Choukr, Juarez Tavares e Luiz Flávio Gomes. São Paulo: Revista dos Tribunais, 2006.

FONTANA, Eliane; REIS, Jorge Renato dos. Direitos fundamentais sociais e a solidariedade: notas introdutórias. In: LEAL, R. G.; REIS, J. R. dos. Direitos Sociais e Políticas Públicas: desafios contemporâneos. Santa Cruz do Sul: Edunisc, 2011.

HABERMAS, Jurgen. Direito e democracia: entre faticidade e validade. V. 2. Rio de Janeiro: Tempo Brasileiro, 2003.

JONAS, Hans. O princípio responsabilidade: ensaio de uma ética para a civilização tecnológica. Tradução original alemão de Marijane Lisboa, Luiz Barros Montez. Rio de Janeiro: Contraponto: Ed. PUC-Rio, 2006.

KANT, Immanuel. Fundamentação da metafísica dos costumes. Tradução de Paulo Quintela. Lisboa: Edições 70, 2007.

KRAUT, Richardt. Aristóteles: A ética a Nicómaco. Tradução de Alfredo Strock. Porto Alegre: Artmed. 2009.

MORUJÃO, Alexandre Fradique. Kant. In: Enciclopédia Luso-Brasileira de Filosofia. Lisboa: Logos ; São Paulo: Verbo, 1991.

NIETZSCHE, Friedrich Wilhelm. Genealogia da moral: uma polêmica. Tradução, notas e posfácio de Paulo César de Souza. São Paulo: Companhia das Letras, 2009.

NODARI, Paulo Cézar. A teoria dos dois mundos e o conceito de liberdade em Kant. Caxias do Sul: Educs, 2009.

OSBORNE, Catherine. O nascimento da filosofia. In: PRADEAU, Jean-François. História da Filosofia. Petrópolis: Vozes; Rio de Janeiro: PUC-Rio, 2011.

ROHDEN, Huberto. Filosofia Contemporânea: o drama milenar do homem em busca da verdade integral. São Paulo: Martin Claret, 2008.

RUSSELL, Bertrand. História do pensamento ocidental: a aventura dos pré-socráticos a Wittgenstein; tradução de Laura Alves e Aurélio Rebello. Rio de Janeiro: Nova Fronteira, 2013. 
SANDEL, Michael j. Justiça. Tradução de Heloisa Matias e Maria Alice Máximo. Rio de Janeiro: Civilização Brasileira, 2011.

SMITH, Adam. Teoria dos Sentimentos Morais. Tradução de Lya Luft. Revisão Eunice Ostrensky. São Paulo: Martins Fontes, 2002.

SOUSA SANTOS, Boaventura de Sousa. Por uma concepção multicultural de direitos humanos. In: SOUSA SANTOS, Boaventura de (org.). Reconectar para libertar. Os caminhos do cosmopolismo multicultural. Rio de Janeiro: Civilização Brasileira, 2003.

\section{Sobre o autor:}

Alexandre Brandão Rodrigues é bacharel em Ciências Militares pela Academia de Polícia Militar do Estado do Rio Grande do Sul (1994). Bacharel em Ciências Jurídicas e Sociais pela Universidade Luterana do Brasil (1999). Especialista em Direito Penal e Direito Processual Penal pela UNIJUÍ (2008). Mestrando do Programa de Pós-graduação stricto sensu em Direitos Sociais e Políticas Públicas da Universidade de Santa Cruz do Sul - UNISC. Defensor Público do Estado do Rio Grande do Sul. Endereço eletrônico: abrandao@mx2unisc.br 